\title{
Da precarização do trabalhador portuário avulso a uma teoria da precariedade do trabalho
}

Silvia Maria de Araújo*

Resumo: A reestruturação organizacional dos portos, a dinâmica tecnológica e um quadro de privatização crescente, desde os anos 1990, criaram um novo referencial para o trabalho, mudando relações técnicas e sociais de categorias históricas, como os estivadores e arrumadores (capatazia). A desregulamentação "oficial" do trabalho portuário, no Brasil, data da implantação do sistema de escala eletrônica. Com sua atividade laboral intermitente e condições contratuais inconsistentes, a situação de precarização dos trabalhadores portuários avulsos antecede as reformulações políticas neoliberais e instiga a proposição de uma teoria da precariedade do trabalho.

Palavras-chave: trabalho; trabalhadores portuários avulsos; modernização dos portos; precarização do trabalho; precariedade do trabalho.

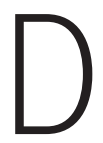
e diferentes perspectivas, os sociólogos do trabalho pensam a condição desigual e vulnerável do trabalho frente ao capital. Marx chegou a esmiuçar a dinâmica da exploração capitalista moderna e a expressar os efeitos das crises sobre a parte remunerada da classe trabalhadora. A denominação precarização do trabalho tem sido aplicada a um processo relativamente recente, ocorrido nas últimas quatro décadas, provocado pelo desenvolvimento do capitalismo moderno globalizado. Embora se expresse pelos efeitos de uma grande transformação que vem afetando o mundo do trabalho, assenta-se na condição de subordinação do trabalhador assalariado e na sua situação de vulnerabilidade em face do capital.

O objetivo deste artigo é compreender o processo de precarização do trabalho, a partir da experiência histórica dos trabalhadores portuários avulsos. Tomando por referência o trabalho no Porto de Paranaguá-PR, a pesquisa analisa o cenário de transformações capitalistas, o processo de modernização dos portos e de gestão da mão de obra portuária. A situação de grandes mudanças e de crise global, nos últimos anos da década de 2000, apresenta a necessidade de sistematizar esse conhecimento identificador das vertentes do trabalho precário posto na ausência ou insuficiência de condições de trabalho, de benefícios sociais, insegurança do emprego, perfis novos de trabalhadores, entre outras questões.
* Socióloga, doutora em ciências da comunicação (USP), pós-doutora em sociologia do trabalho (Universidade de Milão), professora aposentada da Universidade Federal do Paraná (UFPR), presidente da Associação Brasileira de Estudos do Trabalho (Abet), biênio 2011-2013. <silviaaraujo.ufpr@ gmail.com>. 


\section{Transformações capitalistas e o processo de precarização do trabalho}

No século XX, o capital organizado concentrou-se e expandiu-se com uma supervalorização das instituições financeiras que tenderam a dispensar a contribuição do capital produtivo industrial. O cenário de crise mundial da primeira década deste século aponta o processo de acumulação em níveis altos e o aperfeiçoamento da gestão da força de trabalho, para alcançar maior competitividade, elevar a produtividade e garantir a lucratividade.

Desde os anos 1970, o capitalismo se desorientou e, mesmo que a globalização não seja absoluta na realidade das nações, a mundialização do capital marca de forma di-

1. O termo mundialização do capital, cunhado por Chesnais (1996), aplica-se ao quadro político e institucional que se firmou com as políticas de liberalização e de desregulamentação da força do trabalho e das finanças adotadas pelos países capitalistas centrais.

2. Castel (1998: 417) utiliza a expressão sociedade salarial para a realidade da França do século $X X$, identificando-a com movimento de promoção de novas oportunidades aos trabalhadores, ampliação dos direitos e garantias para o trabalho, multiplicação das seguridades e das proteções, pari passu ao processo de acumulação.

3. A condição salarial, estudada por Castel (1998), surge nos anos 1930 , com um processo de diferenciação da condição de assalariamento e a adoção de uma ferenciada a atividade do trabalho. ${ }^{1}$ A globalização tem sido um processo de expansão e hegemonia do sistema capitalista, da transformação do Estado de bem-estar social nos países desenvolvidos, da reestruturação produtiva marcada pela flexibilidade e inovações organizacionais, a partir de setores econômicos chave, da disseminação da tecnologia da informação, levando ao encolhimento da participação do trabalho na produção de riqueza. Desestruturada, a relação de emprego padrão, onde prevalece o trabalhador assalariado formal, o trabalho remunerado que garante reconhecimento social entrou em convulsão com as renovadas crises da acumulação. À existência múltipla e coetânea do trabalho parcial, por tempo determinado, sem contrato, em domicílio, autônomo, precário, associado, solidário, os pesquisadores procuram compreender essa diversidade decorrente dos mecanismos de rebaixamento dos custos do trabalho, de sua desregulamentação e perda de valor do trabalho na sociedade contemporânea.

As crises da acumulação se fazem sentir em todos os países, mesmo naqueles onde se consolidou a sociedade salarial. ${ }^{2}$ No Brasil, a reestruturação produtiva apresentou singularidades com as mudanças mais acentuadas nos anos 1990 e o processo de dilapidação dos direitos à condição salarial de ser trabalhador. ${ }^{3}$ Países capitalistas emergentes, como o Brasil, o México, o Chile e a Argentina apresentaram diferentes impactos aos processos econômicos e sociais sobre o nível de emprego e o mercado de trabalho, como efeitos do processo de globalização, atestando ser a flexibilização do trabalho acompanhada de contínua precarização com consequências sociais, dando feição nova à subcontratação e terceirização.

Em referência aos países desenvolvidos, Castel (1998) entende por precarização do trabalho as formas particulares de emprego que recobrem situações heterogêneas: aquelas sem contrato ou com contratos por tempo determinado, interinidade, trabaIho de tempo parcial e formas "atípicas" de emprego. A precarização do trabalho elenca inúmeras e sobrepostas situações - perda da renda, o trabalho por conta própria, 
trabalho sem carteira assinada, contrato por tempo determinado, insegurança em relação à proteção social, desemprego disfarçado, trabalho desprovido de garantias -, e se apresenta agravada, mais complexa e disseminada na realidade dos países em desenvolvimento. Gilberto Dupas (2001: 154) ensaia uma explicação: cresce o número de pessoas que só consegue trabalho em jornadas muito curtas (subjornadas), ainda que tenha carteira assinada com a "sensação de desproteção" experimentada pelo trabalhador que fez a transição do trabalho formal ao flexível.

O fenômeno contemporâneo - denso e múltiplo - da precarização do trabalho resulta da conjugação e interdependência de recentes processos históricos, como a flexibilização, a informalização, a desregulamentação, a terceirização. A precarização se presta a múltiplos batizados e há que caracterizá-la, distinguindo-se flexibilidade, de flexibilização do trabalho. Flexibilidade é a habilidade de um sistema para assumir diversos estados sem deterioração significativa de custos, qualidade e tempos (e inovação), concebe Salerno (1993) e, no âmbito do trabalho, se expressa na jornada, nos salários, na produção, nos direitos trabalhistas, nas relações de trabalho, na previdência social, no direito do trabalho, na legislação trabalhista, no mercado de trabalho. A flexibilidade do emprego foi conseguida, inicialmente, nos países desenvolvidos, pelo crescimento do trabalho temporário, dos contratos por tempo determinado e da terceirização, nas condições de flexibilidade têm impactos concretos nos locais e ambientes de trabalho e suas formas de operacionalização variam muito, alerta Martin (2001).

A flexibilidade, no entanto, que se propõe a reorganizar as economias de mercado desenvolvidas e fornecer um novo modelo de desenvolvimento, significa um conjunto de formas e de práticas novas na gestão dos recursos humanos: processos de downsizing e reengenharia, substituição do trabalho de tempo integral pelo trabalho parcial, por subcontratação, segundo Sá (2009). Por meio de formas múltiplas de um novo tipo de posto de trabalho, o chamado emprego flexível ou atípico, a flexibilidade faz crescer a produtividade do trabalho e baixa o custo salarial e valoriza o capital; a flexibilidade do emprego pressupõe uma alteração na organização do trabalho, que passa de um conjunto de postos permanentes e estáveis, para empregos individualizados e flexíveis.

Com essa capacidade de adaptar-se, autocorrigir-se, reformar-se, propiciada pela adoção da flexibilidade por princípio, um sistema normativo, como o das relações de trabalho e seus atores coletivos e individuais, vale-se de práticas institucionalizadas, sobretudo das novas tecnologias da informação e da comunicação. Abre-se a possibilidade de reconstituição das relações de trabalho e dos sistemas de produção em bases sociais, econômicas e geográficas inteiramente distintas, afirma Harvey (1993: 177). Pelo fato de as relações de trabalho configurarem um "campo de tensão", exprimem tanto as pressões exercidas pelo mercado no sentido de mercadorização da força de trabalho, quanto as normas sociais e institucionais que asseguram a sua (re- nova disciplina do trabalho, caracterizada pela regulação da produção típica do fordismo. Com o assalariamento, a identidade social advém da posição ocupada pelo trabalhador. Na realidade brasileira, há um crescimento de assalariados na população ativa, entre as décadas de 1930 e 1970, fruto do processo de industrialização. 
lativa) "desmercadorização" (Hyman, 2005: 24). Explícitas ou difusas, compartilhadas ou aceitas pelas partes envolvidas, essas normas institucionalizadas transitam entre a eliminação das causas do conflito e a materialização das formas de regulação das relações de trabalho, como a negociação individual ou coletiva.

Para a realidade brasileira, Paul Singer (1996) enquadra a precarização do trabalho como a exclusão de uma crescente massa de trabalhadores do gozo de seus direitos legais e o agravamento de suas condições. Essa é a chamada reconfiguração das relações produtivas e institucionais, na qual as formas anteriormente estabelecidas de definição de empregos, dos contratos e dos postos de trabalho estão se transformando de tal modo que o próprio conceito de trabalho assalariado é posto em questão, bem como as normas, institutos de proteção e direitos básicos a ele associados (Abramo \& Abreu, 2000: 7).

As práticas sociais de flexibilidade, introduzidas pela reestruturação produtiva e ao sabor do neoliberalismo, da década de 1990, são o conteúdo histórico do processo de flexibilização do trabalho, perceptível nas condições de trabalho e do seu estatuto que se alteram, ao flexibilizar a jornada pela compensação de horas extras, capaz de abranger o conjunto dos trabalhadores, e incluir o trabalho aos domingos e em tempo parcial; ao flexibilizar a organização do trabalho caracterizada pela adaptação do aparato produtivo às flutuações da produção; ao flexibilizar as relações de trabalho e permitir a negociação direta entre patrões e empregados sobre direitos, como o 13은 salário, descanso semanal remunerado, salário-família, adicional de férias, regulados pelo Estado até os anos 1990; ao flexibilizar os empregos, provocando o aumento da informalidade e dos postos de trabalho no setor de serviços, gerando instabilidade de renda; ao flexibilizar o trabalho com o achatamento da hierarquia dos postos de trabalho e reformas, como a multiplicidade de tarefas múltiplas extensivas, o pagamento por incentivo, a jornada de trabalho flexível ajustável à demanda; ao flexibilizar o trabalhador, quando Ihe é cobrada a capacidade resolver problemas, dominar novas e múltiplas tarefas, fazer sugestões sobre melhorias no processo de produção, como funcionar num ambiente de equipe e aceitar o peso crescente dos prêmios pela produção nos seus salários e promoções, segundo Martin (2001: 381). Este é o perfil do trabalhador funcional.

\section{Os trabalhadores portuários}

Um marco na história portuária brasileira é a Lei de Modernização dos Portos, de 1993 (Lei n.o 8.630/93). Desde sua aprovação, é adotado o modelo de exploração portuária, conhecido como landlordport: o Estado é responsável pela administração e investimentos na infraestrutura portuária e a operação dos terminais é cedida à iniciativa privada, que compra equipamentos, contrata mão de obra e impulsiona a 
produtividade. A regulamentação da lei, em 2008, estabeleceu em 25 anos o período de concessão para as empresas.

$\mathrm{Na}$ atual conjuntura econômica, a perspectiva é de crescimento no movimento de mercadorias nas zonas portuárias. Em 2005, 98\% das trocas internacionais se davam por mar e, nos últimos 20 anos, a frota mundial aumentou sua capacidade por dez. Desde o início deste século, o volume de cargas movimentadas nos portos brasileiros cresceu 75\%, passando de 435 milhões de toneladas, em 1999, para quase 770 miIhões de toneladas, em 2008, segundo os dados da Associação Brasileira dos terminais Portuários (ABTP). Avolumam-se também os problemas de logística, com navios ao mar à espera de autorização para atracar e as filas que se prolongam por quilômetros e horas de espera para descarregar a produção. Em diagnóstico da Confederação Nacional da Indústria (CNI), 50\% das empresas exportadoras apontam a infraestrutura portuária como a mais deficiente entre as etapas pós-produtivas. Estudo do Instituto Brasileiro de Pesquisa Econômica Aplicada (Ipea) de 2010 identificou 265 pontos a exigir melhoria nos portos brasileiros, sendo algumas intervenções consideradas essenciais, como dragagem e derrocamento. Obras de ampliação e recuperação de áreas portuárias e dos acessos terrestres pedem hoje investimento de dezenas de bilhões de reais.

O Porto de Paranaguá, estado do Paraná, atua nesse cenário de expansão e movimentou, em 2011, mais de 27 milhões de toneladas de cargas. ${ }^{4}$ Recebeu 2.400 navios no ano de 2010, quando lá circularam 16.500 veículos/mês. Ao comemorar 363 anos, o município de Paranaguá abriga cerca de 140 mil habitantes (IBGE) e, em função de sua importância, detém um PIB de mais de US\$ 6 bilhões. Um levantamento da Associação Comercial, Industrial e Agrícola de Paranaguá (Aciap) estima que 70\% das atividades da cidade estão relacionadas ao porto e a escalada nos indicadores sociais mostra que houve uma variação de $10 \%$ no total da população do município em 10 anos, hoje com mais de 140 mil habitantes. Os empregos variaram 46\% no mesmo período e somam mais de 30 mil postos de trabalho, enquanto o movimento de importação de mercadorias através do porto cresceu 108\%, passando de US\$ 570 milhões para US\$ 1,19 bilhões, as exportações aumentaram em 254\% e movimentaram US\$ 4,14 bilhões, em 2010, segundo dados do Ministério do Desenvolvimento e Superintendência dos Portos de Paranaguá e Antonina.

O porto e a cidade desenvolveram-se para atender a economia exportadora de produtos primários. Nos embarcadouros incipientes de uma Paranaguá fundada em 1648, circulava o ouro das minas e, em 1890, o povoado atingia cerca de 12 mil habitantes. Entre 1935 e 1950, as importações através do porto eram de combustiveis, arame, sal, açúcar, enquanto a tradicional produção de madeira, erva-mate, milho, cereais e o café em grãos respondia pelas exportações. O café começou a ser exportado, em

\footnotetext{
4. Projeto de ampliação dos portos de Paranaguá e Antonina soma R\$ 1 bilhão em grandes obras. Doze novos berços representarão um crescimento de $60 \%$ no tamanho do cais acostável, com a construção de píeres para a atracação de navios. A capacidade de embarque passará para 16 mil toneladas/hora, três berços para movimentação de cargas e um sistema de píeres para granéis, com capacidade para quatro navios (entrevista com o superintendente da Administração dos Portos de Paranaguá e Antonina, em 25 de fevereiro de 2011, <http://www. portogente.com. br/portosdobrasil/ texto. php?cod=3>, acesso em 18 de julho de 2011).
} 
5 Um plano de expansão do porto, na década de 1970, trouxe as obras do Corredor de Exportação, a dragagem do Canal da Galheta para o acesso a navios de maior calado, como os graneleiros, um cais de $2 \mathrm{~km}$, um oleoduto com $90 \mathrm{~km}$ de extensão; estendeu $a$ área de influência por mais de 500 mil $\mathrm{km}^{2}$, chegando a 16 berços, em 2000.
1929, e atingiu mais de 6 milhões de sacas, quando o porto conquistou o título de maior exportador de café do mundo, em $1965 .^{5}$

A economia mundial tem fomentado o crescimento dos portos, mas não ativado a demanda por trabalhadores. Há movimento de expansão, retração e organização da força de trabalho portuária, em diferentes conjunturas. O que vem acontecendo com os estivadores, uma categoria cuja imagem simbólica e real é emblemática no movimento sindical do país e do mundo? Com base em documentos públicos de ações trabalhistas interpostas na Justiça do Trabalho do Paraná, são tecidas as considerações sobre os trabalhadores portuários.

Falar dos trabalhadores nas docas é desvendar uma história de organização ligada ao crescimento do Porto de Paranaguá pautado pela economia. O Sindicato dos Estivadores, fundado em 1903, antecede a primeira lei sindical no país, que data de 1907. Há registro de uma greve em Paranaguá, em 1912. O Sindicato da Estiva Marítima e Terrestre surge em 1919 e, dois anos depois, nasce a União dos Estivadores de Paranaguá. São traços da combatividade na origem dos primeiros sindicatos. Jornais operários das primeiras décadas do século XX relatam a forma inusitada de comunicação entre os que trabalhavam a bordo: os trabalhadores escreviam suas reivindicações com carvão e giz nos porões dos navios e iam disseminando a organização dos trabalhadores por diferentes portos do mundo. Havia até mesmo sessões de leitura coletiva dos periódicos operários nos sindicatos (Araújo \& Cardoso, 1992).

Com a organização do Porto de Paranaguá, em 1935, a administração do porto assume a capatazia (o trabalho em terra) dos maquinistas, guindasteiros, ajudantes dos fiéis de armazéns, amarradores de navios e outros. Capatazes e estivadores reivindicam melhores condições de trabalho. Embora muitas leis trabalhistas - pensões, aposentadoria, jornada de trabalho de oito horas, proteção ao trabalho das mulheres etc. - tenham resultado das lutas dos trabalhadores nos anos 1930, a peculiar dinâmica de trabalho dos portuários avulsos e a fragmentação da categoria apresentam entraves à organização sindical, como provam os processos trabalhistas dos anos 1930, nos quais os estivadores terrestres eram defendidos pelos sindicatos para receber o seu pagamento diário sem reconhecimento de trabalho extra.

O processo de redemocratização de meados dos anos 1940 fomenta a criação de partidos políticos, mas não altera a estrutura corporativa do sindicalismo no país. 0 movimento sindical busca autonomia e legitimação política, investindo em diversas correntes ideológicas. As entidades de classe que surgem nos anos 1950 - como as dos ensacadores, dos portuários, dos condutores autônomos - refletem esse momento de estruturação sindical. Entre os estivadores, a liderança sindical está ligada ao Partido Comunista, tendência dos trabalhadores organizados nos setores públicos da eco- 
nomia nacional, como os ferroviários. Período de crescimento econômico provocado pela industrialização e a inserção do país na divisão internacional do trabalho, esse foi o tom das questões trabalhistas até a década de 1960. Acrescente-se àquelas condições, o desenvolvimento da indústria naval e tem-se o crescimento dos portos. Navios especializados (graneleiros, portacontêineres, petroleiros) e o modo de carregá-los, como o sistema de operação de carga e descarga sobre rodas ou esteiras, levam a movimentação de mercadorias a uma gestão portuária controladora da mão de obra. Essa se organiza para reivindicar seus direitos, diante das condições instáveis de trabalho. ${ }^{6}$

A conjuntura nacional de desenvolvimento econômico expõe a importância da exportação do café para se compreender a atuação sindical. Paranaguá viveu, em 1962, uma experiência solidária dos trabalhadores da orla marítima, com a criação do Fórum Sindical de Debates do Litoral Paranaense, à semelhança do de Santos, uma entidade civil do movimento sindical unificado. Os armazéns abarrotados de sacas de café para exportação, que atingiu naquele ano mais de US\$ 200 milhões em divisas, exigiam contínua atividade dos ensacadores, estivadores, conferentes, portuários e arrumadores. Organizados em setores estratégicos, eles desenvolvem mobilizações capazes de paralisar as atividades portuárias. Parte significativa dos trabalhadores operava em condições adversas de demanda, jornada, remuneração e mesmo de competição e as razões dessa exploração do trabalho manual incluíam o fato de o próprio sindicato administrar o trabalho do transporte do café ensacado. Eram reivindicações do fórum: melhoria das condições de trabalho, taxa de insalubridade, diminuição das pilhas de café (Villa Verde, 1988).

Nos processos interpostos na Justiça contra agências marítimas e a administração do porto, nos anos 1960, os trabalhadores reclamam a ausência de vínculo empregatício, a natureza eventual do trabalho, o pagamento por empreitada, as demissões sem justa causa, que retiram a condição de direitos aos ensacadores, arrumadores, estivadores.

\subsection{Os trabalhadores portuários avulsos e a modernização dos portos}

Com a criação das Delegacias do Trabalho Marítimo (DTM), em 1933, o Estado interveio nas relações de trabalho portuário, a fim de disciplinar a respectiva prestação de serviços, conforme a política trabalhista. Foram atribuições das delegacias por mais de 50 anos: organizar a matrícula dos trabalhadores portuários avulsos (TPA); fiscalizar o trabalho e a escala rodiziária nas entidades estivadoras e sindicatos; quantificar o número de TPAs necessários; impor penalidades aos TPAs; mediar conflitos. Com a promulgação da CLT, em 1943, duas seções (VIII e IX, Cap. I, Título IV) foram destinadas ao trabalho portuário avulso, consolidando a normatização e intervenção estatal das relações de trabalho nos portos.
6. Nos anos 1960, a Administração do Porto de Paranaguá assina convênio para prestação de serviços e assistência aos associados (fornecimento de gêneros alimentícios e produtos

farmacêuticos)

e é organizada a

Comissão Interna de Prevenção de Acidentes (Cipa). Os trabalhadores fundam a Associação dos Portuários de Paranaguá e a União dos Portuários de Paranaguá. 
7. Peação/

Despeação: fixação da carga nos porões ou conveses da embarcação para evitar sua avaria. Peador/despeador ou conexo é o trabalhador que escora a carga com madeira com técnicas de carpintaria.

8. Os estivadores recebem diferentes denominações funcionais: contramestregeral ou do navio, que coordena os trabalhos nos porões, com as instruções do operador portuário e do comandante do navio; contramestre de terno ou de porão, dirige o serviço de estiva nos porões.

\section{Inserida no ordenamento trabalhista pelo Decreto n. 1.574/95, a Convenção 137, que foi ratificada pelo Brasil em junho de 2011, atende à necessidade de assegurar a qualificação do trabalhador portuário e a minorar os efeitos da precariedade do trabalho avulso, por não haver a segurança de um rendimento mínimo ao mês.}

10. A Lei n. $98.630 / 93$ estabelece o fim do monopólio sindical para "modernizar" o trabalho, implantar métodos de processamento de cargas mais eficientes; remuneração adequada ao trabalhador avulso; incentivos às
As atividades de estiva e capatazia são bastante similares. O elemento diferenciador é o local do trabalho: se, a bordo, é competência da estiva; em terra, é competência da capatazia. Estiva é a atividade de movimentação de mercadorias nos conveses ou nos porões das embarcações principais ou auxiliares, incluindo o transbordo, arrumação da carga, peação e despeação, ${ }^{7}$ bem como o carregamento e a descarga, quando realizados com equipamentos de bordo. ${ }^{8}$ Capatazia é a atividade de movimentação de mercadorias, executada na beira do cais, compreendendo recebimento, conferência, transporte, abertura de volumes para conferência aduaneira, manipulação, arrumação e entrega, bem como o carregamento e a descarga de embarcações, quando efetuados por aparelhamento portuário nas instalações portuárias.

São muitas as categorias de trabalhadores independentes do porto: os conferentes, os vigias, os do bloco, os práticos. Os conferentes são contratados pelos agentes de navegação para trabalhar no controle da mercadoria desembarcada ou a embarcar; os vigias cuidam da segurança da embarcação; os trabalhadores do bloco são encarregados da limpeza e da manutenção dos navios atracados ou fundeados. A praticagem é atividade regulamentada e administrada pelo Ministério da Marinha, através da Capitania dos Portos, e os práticos estão organizados em sindicatos desde os anos 1950.

A diversidade de categorias envolvidas e de agentes de mediação da mão de obra torna complexa a gestão e inspeção do trabalho portuário e o seu disciplinamento jurídico. Em 1985, o poder público, por meio da Delegacia do Trabalho Marítimo (DTM), passa a controlar a assiduidade no rodízio dos trabalhadores portuários avulsos, exigindo frequência para permanecer no sistema. Em 1988, a nova ordem jurídica, influenciada pela regulamentação portuária no mundo, busca seguir as recomendações da Organização Internacional do Trabalho (OIT) de proteção ao trabalhador: a Recomendação 145, que garante a livre negociação coletiva, protegendo o trabalho avulso (capatazia, estiva, conferentes etc.) e a Convenção 137, referente às Repercussões Sociais dos Novos Métodos de Processamento de Carga nos Portos, cuja proteção se aplica aos que trabalham de modo irregular. ${ }^{9}$

A política de modernização dos portos brasileiros veio com a Lei n.․ 8.630/1993, referente ao regime jurídico dos portos organizados e das instalações portuárias. Enfatizou a negociação coletiva no setor, fortalecendo os sindicatos, mas descartou o caráter administrativo da intermediação da mão de obra avulsa exercido pelos sindicatos. ${ }^{10}$ A lei criou a figura do Órgão Gestor de Mão de Obra (OGMO) nos portos organizados, como sucedâneo da extinta DTM no controle da matrícula dos portuários, na aplicação de penalidades e na quantificação do número de trabalhadores necessários. Também é função do OGMO administrar e fornecer a mão de obra portuária avulsa, controlando o rodízio, efetuar a remuneração, recolher os encargos e fazer cumprir as normas de segurança e saúde no trabalho. ${ }^{11}$ 
Trabalhador portuário é aquele habilitado a executar atividades realizadas nas instalações de uso público ou privativo, dentro ou fora dos limites do porto organizado, nos casos previstos. A lei estabelece duas formas de trabalho: o trabalho portuário avulso e o trabalho portuário com vínculo empregatício. ${ }^{12}$ Essa é uma inovação, pois antes não era possível o trabalho com vínculo empregatício, salvo na capatazia onde eram empregados das Cias. Docas. Muitas vezes o termo trabalhador portuário designa tanto um gênero de trabalhador (aquele que labora nos portos), quanto aquele registrado no OGMO e cedido, em caráter permanente, com vínculo empregatício, a prazo indeterminado ao operador portuário.

Na atividade portuária, a modernização se expressa na economia de escala, concorrência interportuária, multiplicação das alianças, eficácia logística e a cada adaptação de infraestrutura e equipamentos, reduz-se o número de pessoal empregado. A modernização se traduz na resposta das autoridades portuárias às exigências dos armadores e/ou mantenedores, segundo Malezieux (2008), num quadro de privatização crescente que exige pessoal especializado na condução de máquinas mais aperfeiçoadas (guindastes, pórticos etc.). Dowbor (2002) coloca essa questão técnica:

O processo produtivo avançou para um aprofundamento das divisões técnicas interdependentes, em que o acesso ao trabalho é bastante limitado [...], pois as atividades econômicas ficam dominadas por sistemas empresariais integrados, com muita tecnologia e pouco emprego (Dowbor, 2002: 102).

Os portos operam 24 horas, divididas em turnos de trabalho que variam conforme sua especificidade ( 6 ou 8 oito horas). A lei prevê intervalo intrajornada para repouso e alimentação, podendo haver a prestação de horas extraordinárias de trabalho, quando a partida do navio coincide com o horário da troca de turno da equipe de trabalho. O operador portuário ou tomador de mão de obra elabora as requisições do número de trabalhadores necessários à operação de carga ou descarga ao OGMO, respeitada a composição das equipes de trabalho, prevista em convenção ou acordo coletivo. O OGMO efetua a escala dos trabalhadores, transformando números em nomes por meio do rodízio - sistema de alocação equânime das oportunidades de trabalho entre os trabalhadores avulsos portuários, que somente trabalharão quando chegar a sua vez na fila de oportunidades.

Denomina-se trabalhador portuário avulso (TPA), aquele que, inscrito no OGMO, presta serviços na área do porto organizado, sem vínculo empregatício, a vários tomadores de mão de obra. Não obstante a distinção contida no art. 18 da Lei n.o 8.630/93, os trabalhadores integrantes do registro e do cadastro são todos avulsos, situação que só se altera se o trabalhador for cedido pelo OGMO a operador portuário com vínculo empregatício a prazo indeterminado. A requisição de trabalhadores avulsos era feita relações comerciais, eliminação das barreiras; capacitação profissional; constituição de um Conselho de Autoridade Portuária (CAP), órgão colegiado formado pelos poderes públicos, usuários, operadores e trabalhadores portuários, a fim de estabelecer um regulamento de exploração portuária; horário de funcionamento do porto; valores da tarifa; maior racionalização e otimização no uso das instalações.

\section{O trabalho} portuário regese por alguns princípios: $a$. o negocial: delega aos representantes patronais e laborais, a negociação e a normatização do trabalho portuário avulso. As convenções coletivas de trabalho, no entanto, não retiram as prerrogativas dos OGMOs, entidades revestidas de interesse público: b. o publicista: interesse público é dado pela escalação obrigatória do OGMO e implementação da norma de segurança portuária; c. o da restrição do trabalho: veda a execução de serviços portuários por trabalhador não integrante do sistema; $d$. o da equidade: espécie de isonomia entre os trabalhadores para 
que tenham o mesmo tratamento no acesso ao trabalho, aos cursos, à promoção ao registro e à execução de sua atividade; e. o da multifuncionalidade: as atividades requerem a mesma qualificação de trabalhadores habilitados, independente da categoria; prevê implementação de forma negocial pelas convenções coletivas; f. o da modernização: sinaliza ruptura com o sistema legal anterior do intervencionismo estatal e monopólio dos sindicatos na intermediação da mão de obra avulsa (MTE, 2001).

\section{Num porto} organizado, a operação portuária é um complexo de tarefas interrelacionadas: movimentar manualmente mercadorias, içá-las, conferi-las, arrumá-las etc. (trabalho portuário), requisitado pelo operador portuário, pessoa jurídica, pré-qualificada pela administração do porto, responsável pela direção das operações. pelas chamadas entidades estivadoras (armadores e seus agentes) aos sindicatos das respectivas categorias profissionais; na atualidade, são os sindicatos dos operadores portuários que negociam com os sindicatos de trabalhadores portuários as condições de trabalho. Medidas como essa acompanham a tendência mundial quanto à administração portuária, que recomenda a constituição de Conselhos de Autoridade Portuária (CAP) e a organização coletiva do trabalho, para desviar o corporativismo das categorias envolvidas.

Em remissiva à disputa dos trabalhadores, dada a diversidade das categorias, embora reunidos pela denominação de "trabalhadores avulsos", os portuários vivem o fenômeno da segmentação social. O processo que fragmenta o mercado de trabalho e o conjunto de trabalhadores nos locais de trabalho e em suas ocupações marca com diferenciações os interligados setores econômicos, aguça as disparidades sociais, como uma variante moderna da polarização, e traz à tona uma nova concepção de desigualdades, contraditória com o conceito de modernização, afirmam os sociólogos Kern e Schuman (apud Leite, 1995).

Para a Previdência Social, trabalhador avulso é aquele que, sindicalizado ou não, presta serviço a diversas empresas, sem vínculo empregatício, com a intermediação obrigatória do OGMO. Dada a sua constante alteração de ritmo, a atividade portuária favorece a incorporação de trabalhadores esporádicos, cujo trabalho difere de outras formas descontínuas de prestação de serviços pela subordinação jurídica existente com o tomador de mão de obra. A lei de modernização dos portos (Art. 8o) prevê situações em que é dispensável a intervenção do operador portuário e o interessado, sem necessidade de qualificação, pode realizar a movimentação respectiva, com a própria tripulação dos navios. Outras empresas podem requisitar trabalhadores avulsos junto ao OGMO e essa maleabilidade dá particularidades ao trabalho portuário: não possui vínculo empregatício, nem cumpre jornada específica de trabalho, são condições desfavoráveis em relação à segurança e higiene e não possui garantias de trabalho ou de renda.

Processos encaminhados à Justiça do Trabalho, na década de 1990, demonstram a fragilidade do trabalhador avulso perante a legislação quanto ao adicional de trabalho noturno, pagamento de horas extras, respeito ao intervalo entre jornadas, descanso semanal remunerado, férias de trabalhadores de bloco, arrumadores, estivadores, conferentes. Para aqueles com vínculo ou não junto a tomadores de serviço, como motoristas, auxiliares de manutenção, pedreiros, serventes de limpeza, mecânicos, o teor das ações reclamatórias passa por desvios históricos de função, gratificação de produção, adicional de risco, terceirização ilícita, gratificação de produção, equiparações salariais com servidores portuários. 
Com a lei de 1993, torna-se polêmica a implantação do sistema de escala eletrônica para os trabalhadores avulsos das duas maiores categorias, da estiva e dos arrumadores (capatazia) do Porto de Paranaguá, que já adensavam os componentes históricos daquele tipo de trabalho. As crises desencadeadas com greves e mobilizações dos estivadores colocam em pauta a transição gradativa para a chamada eletrônica dos denominados operadores portuários. Para concorrer a uma oportunidade de trabalho, os trabalhadores avulsos são obrigados a se dirigir duas vezes ao dia (6h30 e 18h30) aos pontos de chamada. Conforme a oferta de serviços é efetuada, a escala "rodiziária" deveria dar igual oportunidade a todos, na forma da lei. Os não contemplados com trabalho devem comparecer 12 horas depois, embora não haja garantia de obter trabalho remunerado na outra escalação.

\section{Precarização do trabalho portuário: de operário a operador}

No início dos anos 2010, os trabalhadores portuários avulsos somavam 40 mil homens, sendo que os estivadores, categoria histórica e simbólica da tradição combativa, não passavam de 16 mil trabalhadores, no Brasil. Aproximadamente 3 mil trabalhadores avulsos estavam ligados ao Porto de Paranaguá e, desses, pouco mais de 1.200 eram estivadores sindicalizados, convivendo em meio à desigualdade de tratamento e de condições de trabalho. Houve diminuição do mercado de trabalho do avulso e da renda, perda de postos de trabalho, em dissonância ao recomendado e regulamentado pela OIT, pois a "conteinerização" e o aumento do uso de tecnologias reduziram postos de trabalho e os custos e aumentaram a produtividade. A Convenção 137 da OIT contempla esse problema, determinando que governos e empresários estabeleçam políticas sociais para garantir uma remuneração mínima aos trabalhadores portuários avulsos e a antecipação de aposentadorias.

O processo de precarização atinge quase todos os setores econômicos, conformando degradação das condições de trabalho, perda de direitos, redução de garantias e benefícios, instabilidade no emprego com indefinição do empregador, ação de mediadores, tornando vulnerável a situação dos trabalhadores. O trabalho portuário avulso nasceu na precariedade e como trabalho manual nato atinge hoje uma situação de multifuncionalidade sem ser um trabalho vinculado. O fato de a legislação de modernização dos portos datar de 1993 com o controle pelo OGMO e anteceder as medidas de reforma do sistema de relações de trabalho adotadas pelo governo, na década de 1990, não justifica a instabilidade permanente do trabalho portuário. A sua precarização precede a história recente da desregulamentação do trabalho no país. Mudanças mais acentuadas configuram uma onda de dilapidação dos direitos sociais e trabaIhistas, naquela conjuntura, e muitos são os processos trabalhistas de portuários que reclamam aviso prévio, 13으 salário, rérias proporcionais, depósito FGTS. Em meio ao modelo econômico neoliberal, as políticas do trabalho foram favoráveis à flexibilização 
dos contratos de trabalho, à desregulação do mercado de trabalho e à transferência de responsabilidade exclusiva para o indivíduo pela trajetória ocupacional, mediante a adoção das políticas de formação e qualificação profissional.

Tradicionalmente, profissionais de manipulação exclusiva de cargas unitárias ou agrupadas, de uso de guindastes rudimentares, os estivadores sempre trabalharam em ambiente de equipe, cooperação e insegurança nos navios. Eram modalidades de emprego particulares: referências familiares, de local de origem, certo poder do grupo organizado. Perderam sua identidade coletiva e o trabalho no cais ou no navio se diversificou. A condução de sistemas complexos de deslocamento de mercadorias a granel e de contêineres e a tendência à privatização dos portos exigem hoje conhecimentos técnicos e fragmentam mais a categoria.

A nova divisão internacional do trabalho é visível no quadro de produtos exportados/ importados por via marítima e mudanças ameaçam o desaparecimento dos estivadores, mesmo o emprego precário decresceu. Quando as máquinas, a tecnologia de embarque e desembarque de cargas, o armazenamento programado e a manipulação controlada chegaram ao setor portuário, nos anos 1990, a flexibilização do trabalho prevaleceu. A participação intermitente do trabalhador na atividade laboral, seja na beira do cais, seja embarcado, a dissolução do modelo assalariado tradicional com mudanças nas condições contratuais (antes informais, orais, ocasionais e depois exigentes de qualificação na alocação da mão de obra, com alterações na jornada), a subocupação, a destruição de postos de trabalho contêm elementos de precariedade. Pela natureza manual da atividade, os trabalhadores portuários avulsos têm um trabaIho altamente parcelizado, que se apresenta em ocasional e fragmentado, reafirmando o fundamento efetivo do processo de produção capitalista: "a separação entre o produto do trabalho e o próprio trabalho, entre as condições objetivas do trabalho e a força subjetiva do trabalho" (Marx, 1975: 665). A permanência dos navios no porto cadencia e intensifica o trabalho dos estivadores que, embora juntos e de forma cooperativa, trabalham como indivíduos isolados, pensa Marx: "todos os agentes da troca produzem nas condições da divisão do trabalho social” (Marx, 1977: 270).

O trabalho dos portuários é regulado por dia ou por tarefa e os tomadores de trabalho sabem aproximadamente a quantidade de trabalho que o trabalhador pode realizar por dia em sua ocupação e pagam-no na proporção da tarefa executada:

[...] as diferenças individuais do salário - que mediante pagamento por empreitada têm maior campo de manobra do que o pagamento por tempo - não constituem senão variações com relação nível de salário. Mas, o pagamento por empreitada tem tendência, quando não refreada por outras circunstâncias, a reduzir inclusive esse nível (Marx, 1978: 133). 
O que distingue o processo de trabalho subsumido, ainda que apenas formalmente aos que diretamente remuneram os trabalhadores, segue a modalidade tradicional. É a escala em que se efetua o trabalho (grupos, conjuntos maiores ou menores de trabalhadores distribuídos por tarefas) e distribuídos por turnos de uma escala designada, que dá amplitude aos meios de produção, sobretudo a utilização da força de trabalho arregimentada (idem: 53). A coerção ao trabalho excedente, a espera do trabalhador para que dele disponham são condições objetivas de uma situação ausente de contrato de trabalho e marcada pela ação dos intermediários, tomadores do trabalho:

\begin{abstract}
Em todas as empresas de Londres existem os chamados "sweaters" (exploradores do suor). Um sweater é aquele que se encarrega de entregar a um primeiro empresário, por um salário habitual, certa quantidade de trabalho, mas que o faz executar por outrem por peço inferior; essa diferença, que constitui seu lucro, é obtida espoliando o suor dos operários que realmente executam o trabalho, e não representa outra coisa senão a diferença entre o valor da força de trabalho que o sweater paga aos verdadeiros operários (Marx, 1978: 131).
\end{abstract}

Os trabalhadores portuários avulsos são mão de obra flutuante, latente, intermitente, cindida, uma ocupação irregular que gera concorrência entre os trabalhadores. Exercem um trabalho manual pesado e desgastante que produz "fileiras de supérfluos", conforme Marx (1975: 744), dispensáveis ainda mais pelo processo de modernização dos portos (infraestrutura e gestão da mão de obra), como se deu com a regulamentação de 1993. "Quando se introduz maquinaria nova ou se amplia a velha, parte do capital variável se transforma em constante" (idem: 742) e dos portuários avulsos é cobrada versatilidade diante do conteúdo do trabalho que se transforma: operam guindastes, equipamentos automatizados, informatizados, deslocam contêineres.

Nesse processo ampliado e historicamente determinado, a acumulação capitalista produz, intensa e extensivamente, uma população trabalhadora supérflua relativamente, isto é, que ultrapassa as necessidades médias da expansão do capital, tornando-se, desse modo, excedente (Marx, 1975: 731)..$^{13}$ Convivem no setor formas diversificadas de relações de trabalho (contratos por tempo indeterminado e vínculo funcional, subcontratações, pagamento por tarefa, por jornada etc.), deduzindo-se que o impacto da privatização de serviços na área dos portos evidenciou insegurança e ameaça ao trabalhador. Os estivadores exercem um tipo de trabalho autônomo, sujeito às permanentes tensões da semilegalidade em que operam, não sem uma nova hierarquização do trabalho, característica do subdesenvolvimento tecnicizado, na expressão de Dowbor ( 2002).
13. Referia-se Marx à indústria europeia do século XIX e vislumbrava a estratégia de o capital dispor de trabalhadores: "Toda a forma do movimento da indústria moderna nasce, portanto, da transformação constante de uma parte da população trabalhadora em desempregados ou parcialmente empregados" (1975: 735). 


\section{Por uma teoria da precariedade do trabalho}

140 capitalismo

"é um processo,

e não uma coisa.

É um processo de reprodução da vida social por meio da produção de mercadorias em que todas as pessoas do mundo capitalista avançado estão profundamente implicadas. Suas regras internalizadas de operação são concebidas de maneira a garantir que ele seja um modo dinâmico e revolucionário de organização social que transforma incansável e incessantemente a sociedade em que está inserido. $\mathrm{O}$ processo mascara e fetichiza, alcança crescimento mediante a destruição criativa, cria novos desejos e necessidades, explora a capacidade do trabalho e do desejo humanos, transforma espaços e acelera o ritmo de vida. Ele gera problemas de superacumulação para os quais há apenas um número limitado de soluções possíveis. Por intermédio desses mecanismos, o capitalismo cria sua própria geografia histórica distintiva" (Harvey, 1993: 307)
Cientistas sociais, como Castel (1998), na análise da sociedade salarial sob a ótica francesa, denominam a realidade contemporânea de "civilização do trabalho", por se construir a partir do trabalho. Na modernização (impulso para transformar as coisas) provocada pela modernidade, o parâmetro tem sido o trabalho assalariado padrão, no qual o pressuposto é o valor instrumental inscrito ao progresso econômico, na expressão de Bauman (2007: 136). O multifacetado fenômeno do trabalho parcial, subcontratado, precário, autônomo, inseguro, terceirizado, implica situação histórica que tem por paradigma um trabalho formal, contratado, efetivo, em tempo integral, com estatuto da condição de emprego, como diz Salerno (1993). Assim, a precarização do trabalho é fenômeno consequente à queda das condições de acumulação do capital que, para se recuperar, impões privações ao componente trabalho na sociedade marcada pelo regime de assalariamento. Seu conhecimento provoca diferentes interpretações e inúmeras designações para um conteúdo complexo, intimamente integrado a outros fenômenos históricos e estruturais do capitalismo, por ser um processo histórico. ${ }^{14}$ Nasce aqui o interesse em aventar traços característicos de uma teoria da precariedade, capaz de compreender a amplitude da precarização e cobrir a diversidade de suas expressões. Na preocupação de Mészáros (2009) está contemplada, por exemplo, uma teoria maior da transição, no sentido de superação do capitalismo. A necessidade de uma teoria emerge do que ele chama crise estrutural do capital, como um fenômeno global, pressupondo a natureza contraditória do capital, capaz de reproduzir condições existentes no pré-capitalismo.

Na sistematização do estado do conhecimento sobre precarização do trabalho - ato ou efeito de tornar precário - a precariedade é um estado ou qualidade de ser, uma condição imposta por fatores ausentes. O estado de precariedade no trabalho é aquele definido pela falta ou escassez de emprego, pela deficiência contratual trabalhista, pela imperfeição na qualidade das condições de trabalho, pela insuficiência de rendimentos, pela perda de direitos e benefícios conquistados historicamente. No setor portuário, a precariedade do trabalho advém de práticas que levaram à redução dos postos de trabalho, à aplicação eletrônica de sistemas de rodízio, ao pouco amparo aos trabalhadores, pressionados pela intermediação tecnológica e de recrutamento da mão de obra.

Trabalho precário é aquele que tem pouca ou nenhuma estabilidade, antonímia de permanente, durável. É precário o trabalho que se apresenta instável, incerto, contingente, inconsistente. Precário é o trabalho parcial, temporário, sazonal, intermitente, é aquele desprovido de resistência e defesa. É também precário o trabalho que se apresenta frágil, vulnerável, desprotegido, impotente diante do capital. Num paralelo próprio de dicionários, saúde precária é o estado débil, fraco do ser humano adoen- 
tado, que inspira cuidados, corre risco de vida. Denotando natureza, algo que lhe é intrínseco, não é atributo (nem lhe atribuído), precário é o trabalho que se encontra em situação incerta, indefinida, dependente. A origem do vocábulo é do latim precariu(m), algo que é obtido com preghiera/prece (de prex, precis, preghiera), com oração, concedido por graça. Em latim, precário designa algo que se obtém por um favor, por benevolência. ${ }^{15}$

A propósito do trabalho assalariado no quadro da economia mundial e, particularmente, no setor portuário, a condição de ser precário, etimologicamente, significa provisório, algo concedido, tomado por empréstimo, seja do Estado, ou do sindicato, seja das empresas, como no caso dos trabalhadores portuários avulsos, uma condição de sua biografia que revela uma tendência histórica persistente. A condição de ser precário diz respeito ainda a aspectos como alheio, estranho, passageiro, que não permanece, remetendo ao caráter alienado do trabalho, em uma nova e caleidoscópica versão.

A ideia de precariedade no trabalho, formulada por Castel (1998), tem como pano de fundo o esboroamento da condição salarial por força do amplo processo de precarização que também afeta parte do conjunto de trabalhadores formais. Sem os dissociar, Sá (2009) distingue os termos precariedade e trabalho precário, esse último, aquele que diz respeito a como o trabalhador se depara com uma situação de emprego irregular, a ausência de proteção.

\begin{abstract}
A precariedade refere-se a uma situação geral de escassez, insuficiência, desestabilização, falta de reconhecimento e apreço social e corresponde a certo "modo de vida" caracterizado pela falta de condições mínimas, que permitam ao ser humano ser um sujeito individualmente ativo (idem, 2009).
\end{abstract}

Com base em aproximações à realidade empírica do trabalho portuário, na ênfase das pesquisas sobre trabalho precário nas ciências sociais, no processo diversificado e disseminado da precarização do trabalho na sociedade contemporânea, alguns traços distinguem o fenômeno da precariedade: a instabilidade do trabalho, leia-se, do emprego; e a vulnerabilidade do ser trabalhador. A instabilidade do trabalho ganha caráter múltiplo pelas modalidades de precarização impostas ao trabalho e se materializam na renda, jornada, proteção, nas condições, contratos, garantias, benefícios etc. À instabilidade laboral, que não permite aos trabalhadores organizarem a sua vida pessoal, associam-se os baixos salários.

A vulnerabilidade do ser trabalhador se expressa em todas as situações de precarização do trabalho que evocam sentimentos humanos compartilhados de desproteção, empobrecimento, ausência de garantias. Configuram-se como situações de vulnera-
15. Na Idade Média, à operação em que bens imóveis eram cedidos por "benévola concessão" - dada certamente a condição de escassez de propriedades para uso temporário mediante um pagamento davase o nome de precária. No latim tardio, precariu $(m) /$ precarius,

correspondia a uma forma de comodato, contrato em que uma pessoa concede a outra o uso gratuito de um bem por período ou sem determinação de duração (Zingarelli, 1996). 
bilidade: o isolamento ou atomização, resultantes da atuação insuficiente de sindicalização para esses trabalhadores (assalariados sem contrato registrado em carteira, pouco representados pelos sindicatos); uma série de perdas, como a redução de perspectiva profissional (contratos temporários, flexibilidade de dispensas); a supressão e/ou não reconhecimento de direitos, como descanso remunerado, férias, licenças de saúde, aposentadoria e regulação dos salários; a descontinuidade da relação de trabalho e imprevisibilidade dos rendimentos, segundo Galeazzi e Holzmann (2011).

O trabalho precário/trabalho flexível tem como pano de fundo as grandes transformações no trabalho, em todos os países: a crescente flexibilidade do emprego, a individualização das condições de trabalho, as diferentes temporalidades na vida laboral e na vida do indivíduo, a desagregação do trabalho. Pari passu às formas flexíveis de emprego, precárias e desregulamentadas, mas expandidas e em vigência na sociedade contemporânea, ocorrem formas organizadas de um trabalho institucional, polivalente e envolvente, estimuladas pela transferência das decisões do plano das empresas para o do indivíduo, responsabilizado coletivamente por sua participação e pelo êxito da atividade produtiva como um todo. André Gorz (2003) afirma que a tendência à racionalização do trabalho com flexibilidade e individualização penetra todos os poros da sociedade moderna e muda o perfil do capitalismo, acirrando a acumulação sutil e dificultando a preservação dos direitos e ganhos dos trabalhadores, bem como de sua organização de defesa. Esta afirmação sinaliza uma nova precarização do trabalho que atinge hoje parcela significativa da população: trabalhadores de todos os níveis e categorias experimentam a precarização sob diferentes aspectos em variados segmentos sociais.

Como apreender o fenômeno da precarização do trabalho em pleno movimento da realidade complexa? Qual a sua natureza histórica e o que a evidencia? Para captar os fenômenos sociais em transição é preciso atentar à reinvenção dos valores modernos, à emergência de novos conflitos, recomenda Sousa Santos (2007), pois nossas representações da hegemonia da modernidade ainda são incompletas para a construção de novos paradigmas de emancipação social, leia-se, de conhecimento produzido e empregado para fins de justiça social. Novas manifestações sociais apresentam a necessidade de conceitos, segundo Arendt (1988: 28):

uma nova expressão, seja um novo vocábulo criado para cobrir a nova experiência, seja o uso de uma antiga palavra, à qual é atribuído um significado inteiramente novo. Isso é duplamente verdadeiro na esfera política da vida, onde o discurso tem o domínio supremo.

O fenômeno da precarização do trabalho aqui se aloja, sua compreensão desloca o conhecimento para o horizonte da modernidade em crise, social e epistemológica, pela falta de respostas plausíveis a problemas que ela própria criou. 
A mesma modernidade, fundada na crença universalista da razão e na supremacia dos indivíduos, paradoxalmente escapa, ao separar e classificar, pois a sua marca é a ambivalência, afirma Bauman (2001). Chama a atenção no processo de precarização do trabalho moderno, a necessidade defini-lo, tirá-lo da opacidade múltipla em que se encontra. O trabalho que se degrada merece uma explicação mais pausada nesta era de uma modernidade cansada. O que significa a precariedade e a precarização do trabalho? Seria a precarização um efeito?

\subsection{Teóricos e a precarização do trabalho}

A denominação precarização do trabalho tem sido aplicada a um processo recente provocado pelo desenvolvimento do capitalismo. Embora se expresse pelos efeitos de uma grande transformação que afeta o mundo do trabalho, fundamenta-se na condição de subordinação do trabalhador assalariado e na sua situação de vulnerabilidade em face do capital. Nesse sentido, já estava inscrito nas formulações teóricas dos clássicos tradicionais das ciências sociais sobre o trabalho.

A categoria precariedade do trabalho ressalta a descrição do fenômeno que decorre da ruptura de vínculos empregatícios ou de sua desestabilização, ou mesmo da acentuação de outras condições de trabalho que se alteram prejudicando o desempenho do trabalhador, como a intensificação da jornada, a desproteção, a redução salarial, a desregulamentação, os empregos terceirizados, a intermitência do trabalho etc. Fala-se, aqui, dos efeitos, das emanações de uma situação que se apresenta de modo diverso em diferentes setores sociais e segmentos de trabalhadores e que afetam o ser social, o trabalhador, física e psiquicamente.

Marx (1975: 776) chegou a perceber os "efeitos das crises sobre a parte remunerada da classe trabalhadora" e essa é a expressão histórica inovadora da precarização do trabalho: decorre de uma situação de crise. Émile Durkheim, em seu tratado sobre a Divisão do trabalho social, aventa a existência de estados que chama de disnômicos, na sociedade industrial, como as grandes crises econômicas. A desregulamentação, sobretudo dos contratos sociais (e os contratos de trabalho são casos típicos), é antevista ao atribuir conteúdo moral à divisão do trabalho, como um fenômeno de densidade das relações sociais na sociedade industrial, criando laços de dependência funcional:

A ação social se faz sentir não só nas relações contratuais, mas também sobre o jogo dessas relações. Pois nem tudo é contratual no contrato. Os únicos compromissos que merecem este nome são aqueles que foram desejados pelos indivíduos e não têm mais origem que a livre vontade. Inversamente, toda obrigação que não foi consentida mutuamente não tem nada de contratual. Assim, em todas as partes onde existe o contrato está submetido a uma regu- 
lamentação que é a obra da sociedade e não das partes, e que se torna cada vez mais volumosa e complicada (Durkheim, 1973: 180).

Ao longo da história moderna, nas situações de crise - dificuldades para manter o processo de acumulação - o capitalismo encontrou saídas e saiu revitalizado. Esses impulsos de superação nutrem-se de um postulado ainda válido sobre a condição de subordinação formal do trabalho ao capital. Esta condição avança historicamente para uma sujeição real do trabalho ao capital, segundo Marx (1975: 585). Esse excedente de trabalho apropriado pelo capitalista varia conforme a produtividade do trabalho e a sua intensidade em adequação ao desenvolvimento das forças produtivas. Decorre desse postulado de produção da sociedade material que a distribuição do tempo de trabalho e do tempo livre não se faz de modo equânime para todos os trabalhadores. Nascem assim desigualdades sociais de natureza estrutural, pois "o capital não é apenas comando sobre o trabalho [...]. É essencialmente comando sobre trabalho não pago" (idem, 1975: 607). Reside aí o segredo da autoexpansão ou valorização do capital: "seu poder de dispor de uma quantidade determinada de trabalho alheio não pago" (ibidem: 613).

O sistema capitalista se reproduz continuamente graças a esta relação de troca e apropriação de um sobretrabalho, que se dá na base do processo de produção e reprodução material-capitalista (Marx, 1975: 667). Trabalhador e capitalista associam-se para produzir e se dividem para repartir o fruto do trabalho pelo pagamento do salário, na reprodução da relação capitalista. Na sociedade complexa é o trabalhador quem, livre e individualmente, vende a sua força de trabalho, em realidade, o trabalhador pertence ao capital antes de vender-se ao capitalista (Idem: 672).

Para o capital crescer e estruturar-se, reproduzir e expandir-se, resguarda o caráter antagônico da produção capitalista: a uma acumulação do capital corresponde uma acumulação da miséria. Há um desequilíbrio intrínseco à relação capitalista, acentuado em conjunturas de crise de acumulação. Mészáros (2009) desenha o colapso do processo de modernização, capaz de tolher o próprio desenvolvimento do capitalis-

16. Crise estrutural se caracteriza pela passagem de uma organização do trabalho rígida para formas flexíveis e desformalizadas de trabalho, próprias das transformações econômicas a partir dos anos 1970, com efeitos sobre o mercado de trabalho, os conceitos políticos e as organizações dos trabalhadores (Altvater, 1995). mo, como uma contradição fundamental do modo de produção capitalista: a emergência de um novo padrão de desemprego, uma tendência socioeconômica que adquire o caráter de um indicador do aprofundamento da crise estrutural do capitalismo atual. ${ }^{16}$ E prossegue:

Quem sofre todas as consequências dessa situação não é mais a multidão socialmente impotente, apática e fragmentada das pessoas "desprivilegiadas", mas todas as categorias de trabalhadores qualificados e não qualificados (MÉszÁRos, 2009: 69).

Esse sofrimento é a precarização, a qual, como um efeito, advém do desemprego, do emprego temporário, da informalidade, da desregulamentação em suas várias for- 
mas, da fragmentação do trabalho, todas, práticas acompanhadas e justificadas por falsos mitos, como o da necessidade e das vantagens da flexibilidade e o da integração das economias numa sociedade globalizada. Há contundência no argumento:

Naturalmente, do ponto de vista do capital, não pode haver respostas para a pergunta: que espécie de alternativa à "economia do trabalho fragmentado" se deveria perseguir a fim de evitar "a capacidade nova de luta entre capital e trabalho"? (Mészáros, 2006: 40).

A situação de crise estrutural capitalista vem se prolongando e modificando intensamente a organização do trabalho e sua participação no processo de acumulação capitalista. Num movimento reversivo do pensamento complementa-se com uma percepção anterior:

A força de trabalho vende-se por dia, por semana etc. [alienação formal do trabalho], mas não é paga senão depois [...] que tenha funcionado. Por conseguinte, em todas as partes, o operário adianta ao capitalista o uso de sua mercadoria, deixa-a ser consumida pelo comprador, credita-a, antes de cobrar seu valor de troca. Em épocas de crise, inclusive quando ocorrem bancarrotas isoladas, é visível que esse constante crédito dos operários em relação aos capitalistas - que surge da natureza especial do valor de uso vendido - não é nenhuma fantasia oca (Marx, 1978: 126).

Qualquer menção à sociedade capitalista não pode carecer de sua condição básica - a relação salarial -, aquela que comporta um modo de remuneração da força de trabalho, o salário - que comanda amplamente o modo de consumo e o modo de vida dos operários e de sua família -, uma forma da disciplina do trabalho que regulamenta o ritmo da produção, e o quadro legal que estrutura a relação de trabalho, isto é, o contrato de trabalho e as disposições que o cercam (Castel, 1998: 419). Ao se quebrar esta condição, instala-se a insegurança no mundo do trabalho e essas são as marcas, as impressões que a precarização deixa no trabalhador. Nesse sentido, o fenômeno histórico da precarização do trabalho já se apresentava inscrito nas formulações sociológicas dos clássicos, tradicionais e contemporâneos. É exatamente essa feição nova de um fenômeno intrínseco à relação capital e trabalho que está a exigir maiores reflexões na direção de uma teoria da precariedade do trabalho.

Abstract: The organizational restructuring of the ports, the technological dynamics and a framework of increasing privatization, since the 1990s, created a new benchmark for work, changing technical and social relations of historical categories, such as stevedores and ushers (wharfage). The 'official' deregulation port work in Brazil set to the implantation of the electronic scale system. With intermittent work activity and inconsistent contractual conditions, the situation of precarization of detached port workers precedes neoliberal political reformulations and instigates the proposition of a precariousness job theory. 
Keywords: work; detached port workers; ports modernization; job precarization; work precariousness.

\section{Referências}

Abramo, Laís; Abreu, Alice. Produção flexível e novas institucionalidades na América Latina. In: Abreu, A. de Paiva (Org.). Produção flexível e novas institucionalidades na América Latina. Rio de Janeiro: Editora UFRJ, 2000, p. 7-23.

ACÓRDÃO INTEIRO TEOR - Recurso de revista. Ação de representação sindical. Operador portuário. Número Único Proc: RR- 78004/2005-022-09-00. Publicação: DJ- 30 Maio 2008. Acórdão - 1a TURMA - GMWOC/pr/sb;

AltVAter, Elmar. Sociedade e trabalho: conceitos e sujeitos históricos. São Paulo: Editora Unesp, 1995.

ANTUNES, Ricardo. Dimensões da precarização estrutural do trabalho. In: DRUCK, M. Graça; FRANCO, T. A perda da razão social do trabalho: precarização e terceirização. São Paulo: Boitempo, 2007.

Araújo, Silvia; CARdoso, Alcina. Jornalismo e militância operária. Curitiba: Editora UFPR, 1992.

AREndT, Hannah. Da revolução. São Paulo: Ática; EdUnB, 1988.

BAUMAN, Zygmunt. Modernidade líquida. Rio de Janeiro: Jorge Zahar, 2001.

— . Lavoro, consumismo e nuove povertà. Troina: Ciità Aperta Edizioni, 2007.

Biblioteca Pública Do Paraná. Documentação Paranaense. Curitiba, Arquivo dos Municípios: município de Paranaguá, s.d.

BRASIL. Presidência da República. Lei n. 8.630, de 25 Fev. 1993. Regime jurídico da exploração dos portos organizados e das instalações portuárias. Disponível em: <http:// www.planalto.gov.br/ccivil_03/leis/l8630.htm>. Acesso em 12 Jul. 2011.

Centro de Memória do Tribunal Regional do Trabalho - 9a Região. Processos de ações trabalhistas (1937-2006). Acervo. Curitiba, 2011.

CHESNAIS, François. A mundialização do capital. São Paulo: Xamã, 1996.

DowBor, Ladislau. O que acontece com o trabalho? São Paulo: Editora Senac São Paulo, 2002.

DuPAS, Gilberto. Economia global e exclusão social. 3.ed. São Paulo: Paz e Terra, 2001. 
Durkheim, Emilio. De la división del trabajo social. Buenos Aires: Schapire Editor, 1973.

ENTREVISTA com Sr. Antonio Carlos Bonzato - presidente do Sindicato dos Estivadores de Paranaguá e Pontal do Paraná (Sindestiva), concedida a Silvia Maria de Araújo, UFPR, Paranaguá, 6 Out. 2011.

FreITAS JR., Gerson. O salto necessário. Carta Capital, 20 Out. 2010, p. 38-41.

GALEAZZI, Irene; HolzMANN, Lorena. Precarização do trabalho. In: CATTANI, A. D.; HolzMANN, L. (Orgs.). Dicionário de trabalho e tecnologia. Porto Alegre: Editora Zouk, 2011, p. 259-265.

GoRz, André. Metamorfoses do trabalho: crítica da razão econômica. São Paulo: Annablume, 2003.

HARVEY, David. A condição pós-moderna. Uma pesquisa sobre as origens da mudança cultural. São Paulo: Loyola, 1993.

— . O enigma do capital: e as crises do capitalismo. São Paulo: Boitempo, 2011.

HYMAN, Richard. Europeização ou erosão das relações laborais. In: ESTANQUE, E. et alii (Orgs.). Mudanças no trabalho e ação sindical: Brasil e Portugal no contexto da transnacionalização. São Paulo: Cortez, 2005. p. 15-44.

LEITE, Márcia. Inovação tecnológica e relações de trabalho: a experiência brasileira à luz do quadro internacional. In: CASTRO, N. A. de (Org.). A máquina e o equilibrista: inovações na indústria automobilística brasileira. Rio de Janeiro: Paz e Terra, 1995, p. 335-360.

MAlEZIEUX, Jacques. Os estivadores: uma corporação ameaçada de desaparecimento; evolução recente do trabalho de manutenção portuária na Europa ocidental: o caso francês. In: DAL Rosso, S.; ForTeS, J. A. (Orgs.). Condições de trabalho no limiar do século XXI. Brasília: Época, 2008, p. 139-146.

MARTIN, Scott. Globalização e imbricamento da flexibilidade do trabalho: perspectivas contemporâneas da indústria automobilística nas Américas (Brasil, México e Estados Unidos). In: GuIMARÃES, N.; MARTIN, S. (Orgs.). Competitividade e desenvolvimento; atores e instituições locais. São Paulo: Editora Senac São Paulo, 2001, p. 379-403.

MARX, Karl. O capital. Lv. I, v. II. 3.ed. Rio de Janeiro: Civilização Brasileira, 1975.

— . Contribuição à crítica da economia política. São Paulo: Martins Fontes, 1977.

— . O capital. Lv. I, cap. VI (inédito). São Paulo: Livraria Editora Ciências Humanas, 1978. 
MÉSZÁROS, István. Desemprego e precarização. In: ANTUNES, R. (Org.). Riqueza e miséria do trabalho no Brasil. São Paulo: Boitempo, 2006, p.27-44.

— . A crise estrutural do capital. São Paulo: Boitempo, 2009.

Ministério Do Desenvolvimento e Superintendência dos Portos de Paranaguá e Antonina. Gazeta do Povo, 5 Out. 2011.

Morgenstern, Algacy. Porto de Paranaguá; contribuição à história; período de 19351985, v. II. Curitiba: Coração Brasil Editora e Empreendimentos, 2006.

MTE. Manual do trabalho portuário e ementário. Brasília: MTE; SIT, 2001.

SÁ, Tereza. As novas regras da exploração: o trabalho precário. 21 Abr. 2009. Disponível em: <http://passapalavra.info/?p=2879>. Acesso em; 15 Jul. 2011.

SAlERno, Mário. Reestruturação produtiva e sindicatos. XVII Encontro anual da Anpocs, Caxambu, 1993.

SINGER, Paul. Desemprego e exclusão social. São Paulo em Perspectiva, v. 10, n. 1. São Paulo, Fundação Seade, 1996.

SOUSA SANTOS, Boaventura de. Renovar a teoria crítica e reinventar a emancipação social. São Paulo: Boitempo, 2007.

SouzA, Maurício Vitor Leone de. Trabalho avulso. Porto de Paranaguá. Escala eletrônica. Intervalo entre jornadas. Renda mínima. Greve. Jus Navigandi, Ano 11, n. 1129, 4 Ago. 2006. Disponível em: <http://jus.uol.com.br/revista/texto/8732>. Acesso em: 14 Mar. 2011. NBR 6023:2002 ABNT.

Tribunal Regional do Trabalho, 9A Região. Junta de Conciliação e Julgamento de Paranaguá. Processo n. 5/68. Arquivo com selo de Acervo Histórico - TRT9, Centro de Memória, Curitiba.

VILLA Verde, Valéria. Fórum sindical em Paranaguá; tecendo um princípio. 1988. Dissertação (Mestrado) - Universidade Federal do Paraná, Curitiba.

ZINGARELLI, Nicola. Vocabulário della lingua italiana. 12 ed. Bologna: Zanichelli Editore, 1996. 